\title{
2 Unequal mobilities, network capital and mobility justice
}

\author{
Tobias Kuttler and Massimo Moraglio
}

\begin{abstract}
In this chapter, we continue our investigation of the gap between realised and unrealised mobility. After focusing on individual mobility needs and preferences in the previous chapter, we now turn to examining notions of unequal mobilities and mobility justice beyond the distribution of accessibility levels. Therefore, in this chapter, we try to understand mobility poverty from a systemic and structural perspective.

Two different approaches to unequal mobilities will be outlined here: first, the question of mobility justice will be discussed and, second, unequal mobilities in times of the networked society. This chapter concludes with final remarks on practical and policy implications.
\end{abstract}

\section{From transport justice and mobility justice}

Access to mobility options is highly uneven according to gender, race, class, income and age. While it is important to analyse how discriminatory practices explicitly prevent the mobility of individuals from different groups, it is also necessary to investigate the historical, spatial and cultural context of uneven mobilities. Discourses and policy debates often fail to analyse these structural aspects and therefore unintentionally overlook the mobility needs of different groups (Sheller 2015 for ethnic minorities; Uteng and Cresswell 2008 for gender aspects).

This is most evident regarding the needs of women because

when policy makers debate mobility systems, or designers implement new technologies, or researchers study new mobilities, they are unconsciously already working within a context of deeply gendered discourses that must be brought to the foreground if we are to understand how planning decisions may be contributing to unequal mobility outcomes for men and women.

(Sheller 2008, 258)

Questions of justice in mobility have been raised more thoroughly recently, most prominently by Sheller (2018) and Cook and Butz (2018). Recent 
debates on mobility justice are at least partially rooted in endeavours to develop a theory of transport justice and equity in transport provision. Therefore, the approach of transport justice will be briefly outlined here before discussing the contours of mobility justice theories.

In the transport justice debate, the most important criterion is equity in accessibility levels. Martens states: "[A] transportation system is fair if, and only if, it provides a sufficient level of accessibility to all under most circumstances" (Martens 2017, 151). From a theoretical standpoint, there are different approaches to "fairness" in transport that define what is a sufficient level of accessibility. These different approaches are variously helpful to understand transport injustice.

In an egalitarian approach to transport justice, the moral guiding principle is that everyone should obtain the same level of service and access. It considers fairness as a matter of relative distribution of benefits and burdens in transportation and focuses on inequality between social groups or geographical areas. Thus, the egalitarian approach asks why certain social groups or geographic spaces and regions have higher or lower accessibility levels, or more or less transport services than others (Pereira, Schwanen, and Banister 2017, 178).

A sufficientarian approach is more directly concerned with transport disadvantages and meeting the basic needs of social groups vulnerable to exclusion. The moral guiding principle "is not that everyone should have the same, but that each should have enough. If everyone had enough, it would be of no moral consequence whether one had more than others" (Frankfurt 1987, 21). Thus, a sufficiency approach in transport provision aims at the avoidance of misery that is experienced under certain thresholds. Accordingly, interventions in transport systems need to prioritise benefiting people below the threshold compared to benefiting people above the threshold (Martens, Di Ciommo, and Papanikolaou 2014, 7).

These two first approaches may be in conflict with each other due to their nature. Furthermore, it is difficult to apply a strict threshold of accessibility levels because the definition of what levels of individuals' activity participation is "reasonable" and "normal" is highly relational and socially, temporally and geographically context-specific.

Thus, a third, somewhat conciliating approach has been proposed, called prioritarianism. Here, the proponents' point of view is that benefits matter and that they matter more the worse off the person is to whom the benefits accrue. In this approach, the moral value of a benefit, or the disvalue of a burden, diminishes as its recipient becomes better off (Casal 2007). Regarding the priority of intervention, such an approach suggests a weighing of benefits that depends on the position of a person in the range of accessibility and service levels. In practical terms, this implies a ranking of population groups according to accessibility levels. The value of the accessibility benefits diminishes the higher a person's accessibility level already is (Martens, Di Ciommo, and Papanikolaou 2014, 8). 
Fourthly, "Capability Approaches" to transport justice have been highlighted, based on the works by Amartya Sen and Martha Nussbaum. In the context of these Capability Approaches, the focus of transport policies should be on guaranteeing all individuals a minimum level of access to key activities that allow basic needs (commerce, education, healthcare, employment) to be met. It should not mean, however, guaranteeing that all people have access to the same transport conditions. This approach faces two challenges: first, the identification of the minimum acceptable thresholds of accessibility, dependent on a given society's values and history and requiring politically democratic, legitimate decisions; and, second, the fact that accessibility is the result of a combination of personal characteristics and social, economic and environmental specifications. The Capability Approach therefore needs accessibility to be addressed as an attribute of individuals (and personal characteristics such as gender, age, social class, disabilities, time and income) interacting with their environment. Many authors rather implicitly follow the Capability Approach, aiming at determining the minimum level of accessibility that a transport system must offer to each vulnerable segment of the population. Yet, not all authors follow this approach explicitly, leading to different interpretations as to how the transport system should evolve (Pereira, Schwanen, and Banister 2017, 178).

More recently, there has been a significant advance to highlight the limits of the transport justice debate. Proponents of mobility justice argue that the approach of transport justice is too limited to understand the full picture of mobility disadvantage. Sheller argues that "[i]ncreasing access to transport [...] will not solve the problem if we ignore the underlying processes and relations that produce mobility injustice, and which tunnel beneath transport (into the body) and beyond the city (into the world)" (Sheller 2018, 15). She further argues that, in order to understand how the movement of people, resources and information are controlled and governed, mobility justice needs to be addressed at different scales. More concretely, this means that mobility should not only be viewed at the mesolevel in terms of everyday transportation, but also on the level of the body (micro-level) and transnational and global levels (macro-levels). Only when viewing unequal mobilities in conjunction with these scales is a theory of mobility justice comprehensive (Sheller 2018, 14). In terms of theoretical underpinnings, this means that a theory of mobility justice needs to pay explicit attention to discrimination and marginalisation along the lines of gender, class, race and caste. Such perspectives allow forms of privilege in, and exclusion from, deliberative processes that presuppose governance and control of movement, including everyday transport, to be identified. Such a theory furthermore includes spatial and "right to the city" perspectives (Sheller 2018, 22-32).

These perspectives follow the understanding that space cannot be containerised into different separated entities such as "cities" or "nations" or other forms of territories. Spaces are rather highly unequal and contested 
and therefore political, and the production of social space - in the sense of Henri Lefebvre - is a highly uneven process. With an approach that is sensitive to the historical, deeply entrenched injustices on the one hand and an understanding of the politics of space and scales on the other, an import step is taken towards envisioning actual freedom to be im/mobile.

Consequently, proponents of mobility justice do not only call for distributive justice; they argue that mobility justice can only be achieved when the power imbalances in access to information, participation and decision-making processes (deliberative and procedural justice), the recognition of historical injustice and oppressions (restorative justice) and a shift in hitherto practised forms of production of knowledge (epistemic justice) are addressed (Cook and Butz 2018, 5-19; Sheller 2018, 30-35).

For our approach to mobility poverty, as developed in this volume, the understanding of mobility justice is crucial. Only when the deeply engrained inequalities and injustices are taken into account can the gap between realised and unrealised mobility be identified. Only then do unarticulated needs, desires and motivations for mobility become uncovered and can be put to debate. Mobility injustice on all scales will be examined throughout this volume in a thorough examination of spatial aspects (Chapters 4-6) and social criteria (Chapters 7-12), both in theory and in the field (Chapters 13-18).

To open up the view even more, the next subchapter will provide further scrutiny of the political economy of differentiated mobilities.

\section{Unequal mobilities in the networked society and the burden of mobility}

The process of contemporary globalisation and economic competitiveness increase the complexity of mobility regimes, including their power relations. It is important to highlight the close ties between communication tools and mobility options because such an interplay allows more effective organisation of everyday life as well as social and business relationships. ICT drives further the extension and differentiation of social networks. It also allows schedules that are ever more complex and individualised living arrangements. Under such framing conditions, in the modern age, power relations in societies are increasingly building on the realised levels of communication and movement, the distinctive factor being the ability to "keep up" with technological innovation and social trends (Hannam, Sheller, and Urry 2006, 12; Shove 2002, 4). It has been argued that these developments further benefit those who already enjoy privileges, while those facing disadvantages may experience additional burdens (Elliott and Urry 2010, 59).

Furthermore, travelling has become a marker for status among young people, slowly replacing other status symbols such as the car (Canzler and Knie 2016, 61). Whenever new technologies emerge, the potential and opportunities to use these technologies change and those innovations may only be accessible to certain sections of the population because of high 
costs, the expert knowledge involved and so on (Cass, Shove, and Urry 2005, 542).

As outlined previously, the range of mobility options is further increasing day by day and so is the potential burden of mobility. In the transformation towards digital and automated societies, everyone's mobility arrangements are - in one way or another - influenced by the friction between entrenched norms and roles and the fast pace of contemporary life. While for many, negotiating these complexities has become part of everyday life, it can be argued that those who face a social or mobilityrelated disadvantage may be overly burdened by coping with the increased necessity of being mobile.

A key concept for understanding differentiated mobilities from a systemic perspective is the concept of "network capital" developed by John Urry. He and his colleagues argue that in the modern mobile society, above all other, it is movement and its related opportunities that have become associated with the understanding of a "good life". Social status, recognition and prestige are gained, maintained and enhanced by a person's degree of personal mobility and associated mobile lifestyles (Urry 2007).

Drawing on Pierre Bourdieu's works, it is argued that mobile lifestyles together with economic, social and cultural capital produce symbolic power that is the prime currency of social distinction and the mechanism for social stratification in contemporary life. Urry coined the term "network capital" to describe the elements needed to gain such power. He defines it as "the capacity to engender and sustain social relations with those people who are not necessarily proximate, which generates emotional, financial and practical benefit" (Elliott and Urry 2010, 59). For an in-depth understanding of mobility poverty, it is necessary to understand how network capital varies between social groups and how accumulation of such capital creates social inequalities.

The degree of network capital a person possesses depends on the degree of access to the following core elements and capabilities (Urry 2007):

- Appropriate documents, passports, visas, money, vaccines, datareadiness, qualifications and so on that enable safe movement from one place to another;

- A capability to connect with others (workmates, friends and family members) at a distance;

- Movement capacities in relationship to the environment - including physical abilities, competencies to access (digital) information and organisational skills;

- Location-free information and contact points; communication devices and mobile data access;

- Appropriate, safe and secure meeting places; and

- Access to technical systems including: cars, road space, fuel, lifts, aircraft, trains, bikes, phones, email and time and other resources to manage all of these, especially when there is a system failure. 
As opportunities for travel and communication increase day by day, mobile lifestyles are not limited to the kinetic elites (Sheller 2018), but have become prevalent in the middle classes. Lifestyles of high mobility are increasingly perceived as the norm and not the exception in modern societies. High mobility or "hypermobility is glamorized, [...] idealized and made desirable in the contemporary world" (Cohen and Gössling 2015, 1667).

Several authors have argued that social media contributes to the new role of long-distance travel, especially using aviation, as a generator of social status among young people. Social media enables a constant comparison of travel patterns, the estimation of personal "travelness" and thus contributes to identity formation and self-construction (Gössling 2017, 163-164; Gössling and Stavrinidi 2015, 736-743). Thus, such forms of travel enable the accumulation of social and network capital at an early age.

Furthermore, the need to sustain growing networks of family, friends and weak ties across larger distance requires regular physical meetings and hence increased travel (Larsen, Urry, and Axhausen 2006, 109-110). Thus, in mobile societies, individuals may experience a state of anxiety about "being disconnected by those moving around, [...] being stuck in place, $[\ldots]$ being too localist and not networked enough" (Elliott and Urry 2010, 47), and therefore being assigned a lower social status.

These examples show that it is important to understand both the inclusionary and exclusionary effects of social networks, the "Janus-faced capacities of social capital" (Schwanen et al. 2015, 132). Social ties are a capital as outlined by Pierre Bourdieu, i.e. a resource which can be accumulated. This represents a power relationship and a power resource. Social capital has an exchange value and is not detached from material resources (and other forms of capital such as cultural capital, Schwanen et al. 2015, 127-128). Indeed, maintaining social ties needs an investment of material resources.

The networked society is thus a society of inclusions and exclusions at the same time. Hence, due to the linkages between network capital, material resources and other forms of capital, it must be assumed that, in the present mobile societies, travel and communication options are highly accessible to the "travel rich", those who are usually also the better off and benefit them more than the travel poor.

Thus, social groups that face social or transport-related disadvantages may also face a higher burden to realise mobility that is needed for nurturing both basic (socially constructed) needs and their social networks. These perspectives have greatly influenced the transport and mobility disciplines in the last 20 years. Often, however, this approach is still a blind spot in transport policy and planning: we should keep in mind how it has become increasingly difficult to translate empirical findings into policy measures and technological solutions. 
This demands an analysis of mobility needs that takes into account how social ties are maintained (or not) and the extent of the "mobility burden" for vulnerable groups needed for establishing social capital. Such analysis needs to consider how vulnerable groups rely more strongly than others on additional assistance in meeting their mobility needs. Apart from a state's measures, this assistance is often support from family and friends.

From a policy perspective, it is argued that network capital should be enlarged and spread as equally as possible in order to lessen social exclusion. "A socially inclusive society would elaborate and extend the capabilities of co-presence to all its members. It would minimize 'coerced mobility', both to improve psychic health and to heighten equality". Transport policy and planning should therefore promote networking and people's freedom to meet each other and conduct relationships over larger distances (Elliott and Urry 2010, 64). Such perspectives stress that this is indeed necessary to increase mobility in addition to accessibility targets.

However, as authors point out, this social target is in conflict with environmental targets, as growing mobility for all presupposes huge and growing supplies of various resources and further drives global warming (Elliott and Urry 2010, ibid). Such an egalitarian demand is furthermore problematic because of an inherent paradox of contemporary mobility.

When networking and mobility are indeed marking social status, increasing the capabilities for movement may rather not create equality in society, but foster individual advancement and a competition for status that is by nature not egalitarian. Kaufmann concludes that "contemporary forms of mobility [...] are as much a factor of inequality as of equality: they constitute a resource that is inequitably distributed within society, while fostering access to other resources inequitably distribute in space" (Kaufmann and Montulet 2008, 54).

\section{Final remarks: practical and policy implications}

As highlighted at the beginning of this chapter, much of the literature on transport justice focuses on accessibility and accessibility poverty. It is widely acknowledged that accessibility is necessary to expand people's freedom of choice and it promotes equality of opportunity regarding employment, health care, education and other basic needs and services. Thus, from the perspective of transport policy, the focus should be on improving access to places, activities and opportunities.

The sole focus on transport and accessibility, however, may overlook the unfulfilled mobility needs of less mobile social groups. The reason for such a blind eye is that accessibility approaches - whether egalitarian or sufficientarian - need to make assumptions either on the level of inequality that is acceptable in a fair society or on a minimum level of accessibility that should be available to everyone. In practice, however, both assumptions 
pose substantial difficulties. First, for an egalitarian approach, it is very difficult to judge the level of inequality that is acceptable in society and, consequently, many studies avoid making clear statements on this question (Pereira, Schwanen, and Banister 2017, 178).

Second, defining a minimum threshold for levels of accessibility is equally difficult; those trying to define such a threshold may fall into the trap of making generalised assumptions about people's needs, with the consequence that diverse preferences of vulnerable social groups may be overlooked (Preston and Rajé 2007, 159). Another weakness of approaches that only focus on transport is that improving accessibility is mostly viewed in the context of social exclusion. The above outlined challenge of defining adequate levels of accessibility is then exacerbated by weak definitions of what it means to be socially included or excluded.

With the transformation of social relationships due to recent advances in communication technology and mobility options, this challenge is further complicated. Cass et al. remind us of the changing conditions of contemporary life:

In [...] an increasingly mobile world the challenge of accessing other people, places and services at some geographical distance is not something fixed and easily measurable. What is necessary for full 'social' inclusion varies as the means and modes of mobility change and as the potential for 'access' develops with the emergence of new technologies [...]. These developments transform what is 'necessary' for full social inclusion. It is important but very difficult to acknowledge the temporal as well as the spatial dimensions of social exclusion, as these relate to the changing spatial and temporal organization of contemporary life.

(Cass, Shove, and Urry 2005, 542)

A practical example of the changing spatial and temporal organisation is the varying and flexible daily schedules of people. To coordinate different aspects of everyday life with the schedules of institutions and people is a demanding task. Only when the varying schedules of households and individuals can be brought in line with the arrangements of transport systems and the varying schedules of facilities and opportunities to be reached can people's (mobility) needs be adequately met.

This leads us to define a relational approach to accessibility in which policies of accessibility should be considered "relational" in their timing and geographies (Qviström 2015). Social networks are crucial for social identity and maintaining a meaningful life, and - in the form of social capital - for acquiring material benefits and social status (Schwanen et al. 2015, 127-128). As outlined above, for those depending on family, friends and other social informal ties as a life-support system (information on jobs, support in travelling), increased need for travel and communication can indeed be a burden. 
The dynamics of social networks are difficult to approach with accessibility perspectives, as they result in very specific and not generalisable mobility needs, which differ substantially from the basic "formal" needs of life.

To summarise, it can be stated that, in the contemporary world, which is characterised by an "infinity of promised or assumed opportunities arising from movement" (Elliott and Urry 2010, 8), accessibility is a necessary, but not sufficient condition for meeting people's diverse needs.

Due to the flexibility of space-time arrangements in everyday life and the transformation of social networks, any action against mobility poverty should also consider it crucial to relieve people from any additional and unnecessary burden related to their mobility. Transport regimes should be customer-friendly, easily accessible not just in terms of physical accessibility but also in term of skills and duties needed to use the service. Due to the increased complexity of transport-related activities, the coordination of transport activities should be kept at basic levels. This applies first to multimodal journeys, but it should not be limited to them. In order to enhance mobility, we state that we need to focus on people's capabilities to access desired destinations and possibly uncover hidden needs.

\section{References}

Canzler, Weert, and Andreas Knie. 2016. "Mobility in the age of digital modernity: Why the private car is losing its significance, intermodal transport is winning and why digitalisation is the key." In Applied Mobilities 1 (1): 56-67. https://doi. org/10.1080/23800127.2016.1147781.

Casal, Paula. 2007. "Why sufficiency is not enough." In Ethics 117 (2): 296-326. https://doi.org/10.1086/510692.

Cass, Noel, Elizabeth Shove, and John Urry. 2005. "Social exclusion, mobility and access." In The Sociological Review 53 (3): 539-555. https://doi.org/10.1111/ j.1467-954X.2005.00565.x.

Cohen, Scott A., and Stefan Gössling. 2015. "A darker side of hypermobility." In Environment and Planning A 47 (8): 1661-1679. https://doi.org/10.1177/0308518 X15597124.

Cook, Nancy, and David Butz. 2018. Mobilities, Mobility Justice and Social Justice. London: Routledge.

Cresswell, Tim, and Tanu P. Uteng. 2008. "Gendered mobilities: Towards an holistic understanding." In Gendered Mobilities, edited by Tanu P. Uteng and Tim Cresswell, 1-12. Aldershot: Ashgate.

Elliott, Anthony, and John Urry. 2010. Mobile Lives. New York: Routledge.

Frankfurt, Harry. 1987. "Equality as a moral ideal." In Ethics 98 (1): 21-43. http:// www.jstor.org/stable/2381290.

Gössling, Stefan. 2017. "ICT and transport behavior: A conceptual review." In International Journal of Sustainable Transportation 12 (3): 153-164. https://doi.org/1 0.1080/15568318.2017.1338318.

Gössling, Stefan, and Iliada Stavrinidi. 2015. "Social networking, mobilities, and the rise of liquid identities." In Mobilities 11 (5): 723-743. https://doi.org/10.1080/1 7450101.2015.1034453. 
Hannam, Kevin, Mimi Sheller, and John Urry. 2006. "Mobilities, immobilities and moorings.” In Mobilities 1 (1): 1-22. https://doi.org/10.1080/17450100500489189.

Kaufmann, Vincent, and Bertrand Montulet. 2008. "Between social and spatial mobilities: The issue of social fluidity." In Tracing Mobilities: Towards a Cosmopolitan Perspective, edited by Weert Canzler, Vincent Kaufmann, and Sven Kesselring, 38-55. Aldershot: Ashgate.

Larsen, Jonas, John Urry, and Kay Axhausen. 2006. Mobilities, Networks, Geographies. Farnham: Ashgate.

Martens, Karel. 2017. Transport Justice. New York and London: Routledge.

Martens, Karel, Floridea Di Ciommo, and Anestis Papanikolaou. 2014. "Incorporating equity into transport planning: Utility, priority and sufficiency approaches." In Proceedings of the XVIII Congreso Panamericano de Ingeniería de Tránsito, Transporte y Logística, Santander, Spain.

Pereira, Rafael H. M., Tim Schwanen, and David Banister. 2017. "Distributive justice and equity in transportation.” In Transport Reviews 37 (2): 170-191. https:// doi.org/10.1080/01441647.2016.1257660.

Preston, John, and Fiona Rajé. 2007. "Accessibility, mobility and transport-related social exclusion.” In Journal of Transport Geography 15 (3): 151-160. https://doi. org/10.1016/j.jtrangeo.2006.05.002.

Qviström, Mattias. 2015. "Putting accessibility in place: A relational reading of accessibility in policies for transit-oriented development." In Geoforum 58: 166-173. https://doi.org/10.1016/j.geoforum.2014.11.007.

Schwanen, Tim, Karen Lucas, Nihan Akyelken, Diego C. Solsona, Juan-Antonio Carrasco, and Tijs Neutens. 2015. "Rethinking the links between social exclusion and transport disadvantage through the lens of social capital." In Transportation Research Part A: Policy and Practice 74: 123-135. https://doi.org/10.1016/j. tra.2015.02.012.

Sheller, Mimi. 2008. "Gendered mobilities: Epilogue.” In In Gendered Mobilities, edited by Tanu P. Uteng and Tim Cresswell, 257-265. Aldershot: Ashgate.

Sheller, Mimi. 2015. "Racialized mobility transitions in Philadelphia: Connecting urban sustainability and transport justice.” In City \& Society 27 (1): 70-91. https:// doi.org/10.1111/ciso.12049.

Sheller, Mimi. 2018. Mobility Justice: The Politics of Movement in an Age of Extremes. Brooklyn: Verso Books.

Shove, Elizabeth, ed. 2002. Rushing Around: Coordination, Mobility and Inequality. https://www.lancaster.ac.uk/staff/shove/choreography/rushingaround.pdf, accessed 6 May 2020.

Urry, John. 2007. Mobilities. Cambridge: Polity Press.

Uteng, Tanu P., and Tim Cresswell, eds. 2008. Gendered Mobilities. Aldershot: Ashgate. 